\title{
AS VERTENTES DO CONSUMO SUSTENTÁVEL: UM ESTUDO COMPARATIVO ENTRE CONSUMIDORES COM FORMAÇÃO AMBIENTAL E CONSUMIDORES EM GERAL
}

\author{
ASPECTS OF SUSTAINABLE CONSUMPITION: \\ A COMPARATIVE STUDY OF CONSUMES WITH FORMAL EDUCTION \\ IN THE ENVIRONMENTAL AND CONSUMERS IN GENERAL
}

\section{Paulo Henrique Burguesi Pacheco \\ Graduado em Gestão Ambiental pela \\ Universidade de São Paulo (São Paulo/Brasil).}

Hermes Moretti Ribeiro da Silva

Doutor em Administração de Empresas pela Fundação

Getulio Vargas (São Paulo/Brasil). Professor assistente na Universidade

Estadual Paulista Júlio de Mesquita Filho (São Paulo/Brasil).

\section{Eduardo Eugênio Spers}

Doutor em Administração pela Universidade de São Paulo (São Paulo/Brasil). Professor associado na Universidade de São Paulo (São Paulo/Brasil).

\section{Kavita Miadaira Hamza}

Doutora em Administração pela Universidade de São Paulo (São Paulo/Brasil).

Professora da Faculdade de Economia, Administração e Contabilidade da

Universidade de São Paulo (São Paulo/Brasil). 


\section{RESUMO}

A prática do consumo sustentável vem sendo discutida por instituições, governos e especialistas, que defendem que a mudança na forma de consumir pode ajudar a minimizar alguns dos problemas da degradação ambiental. Alguns estudos apontam que cada vez mais consumidores buscam consumir de forma sustentável, porém ainda faltam estudos que comparem grupos com características distintas, a fim de verificar se tais diferenças influenciam seus comportamentos. Neste sentido, esta pesquisa foi feita a partir da Escala de Consumo Sustentável proposta por Ribeiro e Veiga (2011) e aplicada com dois grupos de consumidores, sendo o primeiro formado por 172 pessoas com algum conhecimento em causas ambientais e o segundo formado por 210 pessoas sem comprovação de conhecimento na área. Os resultados apontaram que existe uma tendência ao consumo sustentável entre ambos os grupos de consumidores, porém o nível de engajamento entre as pessoas inseridas em áreas ambientais se mostrou bem maior que as pessoas sem este viés ambiental.

Palavras-chave: Consumo sustentável. Comportamento do consumidor. Sustentabilidade.

\section{ABSTRACT}

The practice of sustainable consumption has been discussed by instituitions, governmentes and experts, who defend that change in this form of consumption can help minimize some of the problems of evironmental degradation problems. Some studies indicate that more and more consumers seek to consume in a sustainable way, but there are still studies that compare groups with different characteristics in order to verify if such differences influence their behaviors. In this sense, this research was based on the scale of sustainable consumption proposed by Ribeiro and Veiga (2011) and applied with two groups of consumers, the first one being composed of 172 people with some knowledge of environmental causes and the second group of 210 people without proof of knowledge in the area. The results indicated that there is a trend towards sustainable consumption between both groups of consumers, but the level of engagement among people inserted in environmental areas has shown to be much higher than people without this environmental bias.

Keywords: Sustainable consumption. Consumer behavior. Sustainability. 


\section{INTRODUÇÃO}

Ganhando força a partir da década de 1970, os estudos sobre o comportamento do consumidor ecologicamente responsável tentam segmentar este mercado promissor, uma vez que a ideia do termo, consumo sustentável, vem se difundindo entre a população, o governo e as empresas.

Segundo o Ministério do Meio Ambiente (2016), consumo sustentável envolve a escolha por produtos fabricados com menos recursos naturais, que sejam produzidos a partir de uma forma legal de trabalho e que possam ser reciclados ou reaproveitados de forma simples. Além disso, o consumo deve ser feito apenas quando necessário, e os produtos devem ter sua vida útil estendida ao máximo.

Para demostrar o quanto o consumo sustentável está presente na sociedade, foi feita uma pesquisa para verificar o quanto selos ou rótulos ambientais impactam na decisão de compra dos consumidores brasileiros. $O$ instituto de pesquisa e opinião pública Market Analysis em parceria com o Instituto Brasileiro de Defesa do Consumidor (IDEC) realizaram um estudo apresentando 27 selos ambientais para 906 consumidores adultos de 11 capitais brasileiras. A pesquisa apontou que oito em cada dez brasileiros conseguiram identificar pelo menos um dos selos (INSTITUTO AKATU, 2016).

A pesquisa, que também explorou o impacto destes selos na decisão de compra por um produto sustentável, apontou que quatro em cada dez consumidores, representando 39,9\% da amostra, admitiram que este tipo de propaganda impacta positivamente na decisão de compra deste bem, outros 23,1\% da amostra afirmaram que, embora os selos influenciem a compra, outras características do produto também são analisadas para se fechar o negócio, e o restante (37\%) demonstrou indiferença quanto aos símbolos (INSTITUTO AKATU, 2016). Os dados desta pesquisa indicam que o consumidor está atento a novas formas de consumo.

Macedo e Ferrari (2014) defendem que as empresas estão se esforçando e sendo obrigadas pelo governo a fornecer produtos e serviços regulamentados dentre a esfera ambiental, abraçando, assim, a causa e os anseios de seus clientes, satisfazendo a sociedade como um todo.

Além disso, empresas que produzem ou prestam serviços com menor impacto negativo no meio ambiente, assim como as que possuem programas sociais, são diferenciadas e apresentam melhor desempenho financeiro e longevidade (MOREIRA; SOARES, 2008).

Hoje, além destes fatores, podemos destacar também a crescente inclusão de pessoas em redes sociais, onde a comunicação pode ser considera um fator ímpar para colaborar com a sustentabilidade nas empresas (MACEDO; FERRARI, 2014) que estão abordando estratégias de marketing verde e utilizando isto como vantagem competitiva (CHEN; CHAl, 2010). 
Entre os pesquisadores, são muitos os autores que propõem estudar o consumo sustentável prezando pela mensuração quantitativa de comportamentos e atitudes relacionados à conduta ambientalmente correta (GONÇALVES-DIAS et al., 2009). Dentre eles, destacam-se Ribeiro e Veiga (2011), que propõem uma escala de Consumo Sustentável testada e aplicada no Brasil. O trabalho inicial realizado em 2009 com 512 estudantes universitários brasileiros foi a base da escala que conta com 13 itens, subdivididos em quatro dimensões, sendo: consciência ecológica, economia de recursos, reciclagem e frugalidade, dimensões estas que envolvem todo o processo de obtenção, uso e descarte de um bem ou serviço. Para Ribeiro e Veiga (2011), a escala pode ajudar a investigar causas relacionadas entre os traços de personalidade e consumo sustentável.

Dado esse contexto, o objetivo geral deste trabalho é comparar o nível de prática de consumo sustentável, entre consumidores em geral - recém-saídos de suas compras em supermercados - e consumidores estudantes de cursos de graduação em meio ambiente. Este objetivo geral desdobra-se nos seguintes específicos: (a) identificar a pré-disposição ao consumo sustentável entre consumidores em processo de formação ambiental e consumidores supostamente sem esta formação; (b) verificar se a aplicação da escala proposta por Ribeiro e Veiga (2011), em grupos de consumidores supostamente orientados ou não ao consumo sustentável, apresenta diferenças significativas.

Portanto, a questão de pesquisa é: quais as similaridades e diferenças entre os consumidores com formação ambiental e consumidores em geral quanto ao nível de prática de consumo sustentável?

Com o estudo, espera-se contribuir com as implicações teóricas, gerenciais e a pré-disposição relacionadas à prática do consumo sustentável, podendo utilizar os resultados aqui encontrados em comparações com outras pesquisas.

$\mathrm{O}$ artigo se divide em uma explanação sobre o consumidor ecologicamente consciente, consumo sustentável e sobre escalas de consumo sustentável já utilizadas, seguidos da metodologia aplicada para a coleta de dados e a análise dos resultados obtidos.

\section{FUNDAMENTAÇÃO TEÓRICA}

\subsection{CONSUMIDOR ECOLOGICAMENTE CONSCIENTE}

Anderson Jr. e Cunningham (1972), são alguns dos autores que podem ser considerados como precursores dos estudos objetivando a compreensão do consumidor de produtos considerados ecologicamente corretos (GONÇALVES-DIAS et al., 2009). Estes estudos iniciais tinham por objetivo identificar e analisar os valores, as atitudes e os comportamentos que estes consumidores demostravam possuir para diferenciá-los dos consumidores comuns (SCHAEFER; CRANE, 2005). 
A postura que este consumidor possui geralmente está relacionada às suas características individuais (VERMEIR; VERBEKE, 2008), e a forma que este consumidor vive e se posiciona a favor ou contra assuntos envolvendo o meio ambiente definem sua consciência ambiental (GONÇALVES-DIAS et al., 2009). A consciência ambiental, portanto, pode ser composta por elementos cognitivos, atitudinais e comportamentais (SCHLEGELMILCH; BOHLEN; DIAMANTOPOULOS, 1996). Para Anderson Jr. e Cunninghan (1972), dentre estes elementos, as características pessoais relacionadas aos relacionamentos pessoais e com a sociedade são as mais eficazes para definir consciência social responsável.

Com o aumento da consciência ecológica e a transformação da questão ambiental como uma prioridade estratégica para a sobrevivência, empresas têm procurado atuar de forma mais sustentável (STRAUGHAN; ROBERTS, 1999). Para Peattie (2001), o engajamento ecológico destas empresas é apenas para estar próximo de consumidores que se importam e possuem responsabilidades com o meio ambiente. Os consumidores, por sua vez, têm se informado sobre as consequências de suas atitudes e estão criando consciência de que suas compras devem ser feitas de forma responsável, e de empresas com comportamentos ecologicamente corretos (FRAJ; MARTINEZ, 2007).

Seja feito de forma interesseira ou não, a mudança da forma de produção que as empresas estão buscando está ajudando a minimizar os impactos no meio ambiente e também na conscientização dos consumidores sem formação e conhecimento ambiental, o que é de extrema significância uma vez que, segundo Ebreo e Vinning (2001), os avanços tecnológicos para minimizar os efeitos negativos na natureza não são suficientes para diminuir significativamente a degradação ambiental, e que somente com a ação individual e das comunidades poderemos ter resultados mais promissores quanto à sustentabilidade.

\subsection{CONSUMO SUSTENTÁVEL E ALGUNS ESTUDOS}

Abordado durante a Conferência das Nações Unidas Rio 92, o consumo ganhou um capítulo na Agenda 21 global. O capítulo 4 da referida Agenda traz seu título "Mudança dos Padrões de Consumo", apontando para a necessidade de mudarmos os padrões insustentáveis de produção e consumo e para a necessidade da criação de políticas e estratégias nacionais que influenciem na mudança da forma de se consumir (BRASIL, MINISTÉRIO DO MEIO AMBIENTE, 2016). Assim como a Agenda 21 global, diversos estudiosos abordaram este tema no decorrer dos últimos anos.

Consumo sustentável, consciente, verde, responsável e ecologicamente correto são algumas denominações dadas ao longo do tempo, por diversos autores, para o consumo feito de forma inteligente, envolvendo apenas a necessidade e prezando pela minimização de impactos ao meio ambiente. Para Portilho (2010), além do crescimento populacional, da escassez de alimentos e do aumento da degradação 
ambiental, podemos destacar outros fatores que estão ligados ao surgimento destas expressões de consumo ecologicamente correto, dentre eles a responsabilidade social surgida na década de 1980 por parte das empresas e a preocupação das pessoas perante o consumo e o impacto que o mesmo pode trazer para a sociedade e o meio ambiente (PORTILHO, 2010).

Ribeiro e Veiga (2011) utilizam a expressão consumo sustentável e o descrevem como sendo a escolha por produtos e serviços ecologicamente corretos, cuja vida útil seja estendida ao máximo, produzidos a partir da economia de recursos e que sua reutilização e seu reaproveitamento por meio da reciclagem sejam eficientes.

Ottman (1993), Fraj e Martinez (2007) são alguns dos autores que abordam o termo consumo ecologicamente consciente, onde os consumidores avaliam e escolhem consumir produtos que causem 0 menor dano possível ao meio ambiente. Nesta linha de pensamento, priorizar "o respeito" pelos recursos ambientais, explorando-os de forma correta e sustentável, é um fator chave para que futuras gerações possam usufruir destes bens sem comprometer o atendimento de suas necessidades (HANSEN; SCHHARDE, 1997).

Para Shamdasani, Chon-Lin e Richmond (1993), o consumo sustentável vai além do ato da compra consciente; abrange também comportamentos em prol ao meio ambiente, como por exemplo, utilizar menos vezes o automóvel, ajudar na reciclagem dos produtos separando em casa os diferentes tipos de resíduos, prezar pela economia de recursos e energia, buscando assim a frugalidade e o desenvolvimento de uma consciência ecológica.

Fontenelle (2010) utiliza várias nomenclaturas como variantes do consumo responsável, cada uma delas tendo definições específicas. Consumo consciente: relacionado ao impacto individual do consumo; consumo verde: consumo feito a favor de minimizar os impactos na natureza; consumo sustentável: manter condições para que as futuras gerações possam usufruir de recursos sem escassez; consumo ético/ ativista: consumo relacionado ao espaço e conflito; consumo eficiente/racional: consumir o que realmente é necessário; consumo saudável: relacionado à saúde do indivíduo; consumo responsável: engloba todas as categorias anteriores, prezando por não causar danos.

Pinto (2011), assim como Fontenelle (2010), prefere utilizar o termo consumo responsável como sendo a expressão para esta forma de consumir sustentavelmente. Para ele, o consumo responsável está associado a ter consciência do significado da sustentabilidade em todos os seus aspectos, ter responsabilidades para consumir de forma correta além de repassar estas ideias. Dentro de consumo responsável, Pinto (2011) inclui como variante o consumo consciente, que para ele envolve ética e responsabilidade socioambiental, e também o consumo sustentável como sendo o consumo inteligente 
feito de forma que garanta a sustentabilidade do que é consumido, permitindo que as futuras gerações possam usufruir do mesmo.

Neste presente artigo, será utilizada a expressão consumo sustentável, a mesma utilizada por Ribeiro e Veiga (2011), justamente por ser tema da escala escolhida para a mensuração dos dados desta pesquisa - Escala de Consumo Sustentável -, descrita e discutida no tópico seguinte.

\subsection{ESCALAS DE CONSUMO SUSTENTÁVEL}

No decorrer do tempo, foram realizados muitos estudos para investigar e identificar o consumidor de produtos ecologicamente corretos, quais são suas características e como estas estão em processo de mudança mediante os cenários vividos atualmente (GONÇALVES-DIAS et al., 2009).

Maloney e Ward (1973) alertam para a necessidade de mudarmos a forma de consumir. Para eles, é necessário um consumo mais consciente e inteligente para combater a degradação ambiental. Defendem que descobrir como a população se relaciona com o ambiente e como ela enxerga sua degradação é o primeiro passo para incentivar a mudança de comportamentos insustentáveis para comportamentos sustentáveis.

Maloney, Ward e Braucht (1975) criaram uma escala ambiental, composta por 45 itens e dividida em quatro dimensões: comprometimento verbal; comprometimento real; grau de envolvimento afetivo com questões ambientais e conhecimentos sobre ecologia. A escala foi desenvolvida para identificar quais variáveis representam o consumidor ecologicamente consciente.

Uma nova escala foi criada por Roberts (1996), a Ecologically Conscious Consumer Behavior (ECCB), escala composta por indicadores comportamentais relacionados ao consumo ecologicamente consciente. Com a escala, Roberts (1996) conseguiu classificar aproximadamente 90 milhões de americanos adultos como sendo consumidores de produtos e serviços ecologicamente sustentáveis, equivalendo a $58 \%$ dos consumidores norte-americanos.

Gonçalves-Dias et al. (2009) desenvolveram uma nova escala objetivando descobrir quem é o consumidor de produtos ecologicamente corretos. Aplicada e desenvolvida para a realidade do Brasil, a escala foi finalizada contendo 16 itens, sendo estes subdivididos em 5 categorias: consumo engajado; preocupação com o lixo; boicote via consumo; mobilização e ambiente doméstico.

Ribeiro e Veiga (2011) propuseram uma nova escala desenvolvida para estudar o consumo sustentável. Também desenvolvida e aplicada na realidade brasileira, a escala final é composta de 13 itens subdivididos em 4 categorias, consciência ecológica, economia de recursos, reciclagem e frugalidade, onde: (a) Consciência Ecológica: retrata a fase de aquisição, indicando as preferências dos consumidores 
por produtos ecologicamente corretos; (b) Economia de recursos: retrata a fase de uso, destacando o não desperdício de água e energia elétrica; (c) Reciclagem: retrata a fase de descarte, lembrando o cuidado com o meio ambiente no fim do ciclo de vida dos produtos; (d) Frugalidade: pode ser considerada uma categoria híbrida da escala, na medida que se refere à compra de produtos usados e preocupação em reutilizar os produtos sempre que possível.

Estas categorias englobam as três fases de um produto: aquisição (pré-uso), uso e descarte (pós-uso), assim como as atitudes que as pessoas podem ter em relação à economia de recursos, ao apoio a empresas cuidadoras do meio ambiente e a um estilo de vida menos impactante na natureza (RIBEIRO; VEIGA, 2011).

A escala foi aplicada em 512 estudantes de graduação, divididos em dois estudos. Primeiramente, em um estudo exploratório, 302 estudantes responderam uma escala inicial composta por 20 itens. Após análises de dimensionalidade e confiabilidade, alguns itens foram excluídos por apresentarem baixa qualidade. Um novo estudo confirmatório e conclusivo foi realizado com 200 estudantes. Neste o resultado foi satisfatório, apresentando medidas de maior qualidade e confiabilidade. Contando com 13 itens, a escala apresentou variância acima de 50\% na maioria dos itens (RIBEIRO; VEIGA, 2011).

Apesar de Ribeiro e Veiga (2011) argumentarem que a escala necessita de melhorias ao apresentar itens com baixa confiabilidade, assumem que a mesma pode ajudar a investigar causas relacionadas aos traços de personalidade e ao consumo sustentável.

As diferentes escalas de mensuração acima citadas buscam verificar como se dá a prática de consumo sustentável. No entanto, a escala proposta por Ribeiro e Veiga (2011) foi a escolhida para ser utilizada neste trabalho por ser atual, apresentar resultados satisfatórios e por ser adequada à amostra pesquisada, que apresenta diferentes características quanto ao conhecimento ambiental. Em um trecho de suas considerações finais, Ribeiro e Veiga (2011) sugerem "investigar sua validade preditiva, aplicando-a em amostra de pessoas sabidamente engajadas na defesa do meio ambiente" (RIBEIRO; VEIGA, 2011, p. 57).

Outros estudos vêm utilizando escalas semelhantes em diferentes periódicos e em situações relacionadas a diversos contextos, como o problema ambiental do clima (SALEEM; EAGLE; LOW, 2018), das gerações (VEIGA-NETO et al., 2018), do consumo de alimentos (HANSEN; SØRENSEN; ERIKSEN, 2018) e automóveis (MATSUMOTO; CHINEN; ENDO, 2018).

\section{METODOLOGIA}

A partir do objetivo da pesquisa, que possui caráter quantitativo e descritivo, o método de pesquisa survey (entrevista estruturada direta) se mostrou o mais adequado para levantar os dados que a compõem, uma vez que envolve grande número de entrevistados (MALHOTRA, 2006). 
O questionário foi utilizado para colher os dados desta pesquisa pois garante padronização nas respostas, possibilitando uma boa comparação dos dados entre os entrevistados (MALHOTRA, 2006).

Com intuito de comparação do consumo sustentável, foram elaborados dois questionários, sendo um deles específico para os consumidores estudantes de cursos de graduação em meio ambiente e outro para consumidores em geral do varejo supermercadista. Os questionários apresentam a Escala de Consumo Sustentável proposta por Ribeiro e Veiga (2011), demostrada no quadro 1, composta por 13 itens subdivididos em quatro dimensões, sendo elas, consciência ecológica, reciclagem, frugalidade e economia de recursos. Em cada um dos itens, foi utilizada a escala do tipo likert de cinco pontos, conforme indica Malhotra (2006). Os valores foram atribuídos à frequência com que os entrevistados praticam cada um dos 13 itens, sendo (1) nunca; (2) nunca - às vezes; (3) às vezes; (4) às vezes - sempre; (5) sempre. Aos itens reversos da tabela 9 e 12 foram atribuídos valores invertidos da escala.

\section{Quadro 4 - Escala de Consumo Sustentável}

(continua)

\begin{tabular}{|l|l|}
\hline Itens & Dimensão \\
\hline Você separa objetos de metal (latas de alumínio, óleo, extrato de tomate, etc.) para reciclagem. & Reciclagem \\
\hline $\begin{array}{l}\text { Nas eleições para cargos públicos, você prefere votar em candidatos que tem posições firmes } \\
\text { em defesa do meio ambiente. }\end{array}$ & Consciência ecológica \\
\hline Você busca maneiras de reutilizar os objetos. & Frugalidade \\
\hline Você tenta consertar as coisas em vez de jogá-las fora. & Frugalidade \\
\hline Você separa vidro (garrafas de cerveja, refrigerante, frascos de perfumes, etc.) para reciclagem. & Reciclagem \\
\hline Você para de comprar de uma empresa que mostra desrespeito pelo meio ambiente. & Consciência ecológica \\
\hline Você compra produtos usados. & Frugalidade \\
\hline $\begin{array}{l}\text { Você muda de marca para comprar de empresas que demonstram maior cuidado com o meio } \\
\text { ambiente. }\end{array}$ & Consciência ecológica \\
\hline $\begin{array}{l}\text { Você deixa aparelhos como a televisão e computador ligados mesmo quando não está } \\
\text { utilizando. }\end{array}$ & Economia de Recursos \\
\hline Você separa papéis (jornais, revistas, livros, cadernos, etc.) para reciclagem. & Reclagem \\
\hline
\end{tabular}


(continuação)

\begin{tabular}{|l|l|}
\hline Itens & Dimensão \\
\hline $\begin{array}{l}\text { Você fecha as torneiras da pia ou do chuveiro quando está ensaboando os objetos, o corpo ou as } \\
\text { mãos. }\end{array}$ & Economia de Recursos \\
\hline $\begin{array}{l}\text { Você deixa luzes acesas sem necessidade. } \\
\begin{array}{l}\text { Você separa embalagens de plástico (sacolas, garrafas PET, copos descartáveis, etc.) para } \\
\text { reciclagem. }\end{array}\end{array}$ & Economia de Recursos \\
\hline
\end{tabular}

\section{Fonte: Adaptado de Ribeiro e Veiga (2010)}

Além da Escala de Consumo Sustentável, foram elaboradas duas perguntas abertas envolvendo o mesmo conceito, porém elaboradas especificamente para cada grupo estudado. A escolha de uma pergunta aberta no questionário foi propor que o pesquisado pudesse expressar, de forma detalhada, sua posição com relação ao consumo sustentável, e para que refletisse sobre esta prática, objetivando, assim, verificar se o discurso sobre a preocupação ambiental e estilo de vida se confirmam no comportamento de compra destes consumidores.

Para os estudantes de graduação com foco em questões ambientais, a pergunta foi: Quando você está fazendo suas compras em supermercados, você pensa em preservar o meio ambiente? Explique e dê exemplos. E para consumidores do varejo, a mesma pergunta adaptada: Durante suas compras e escolha dos produtos, você pensou em preservar o meio ambiente? Explique e dê exemplos.

A terceira e última parte do questionário foi o levantamento de dados demográficos para caracterização do respondente, sendo: gênero (masculino ou feminino), idade (em anos completos), nível de escolaridade (não alfabetizado, primário incompleto, primário completo, ensino médio incompleto, ensino médio completo, superior incompleto, superior completo, pós-graduação incompleta, pós-graduação completa) e renda familiar (expressa em $\mathrm{R} \$$ ).

O questionário contemplou ainda uma breve explicação dos propósitos da pesquisa, além do agradecimento pela colaboração.

Com o intuito de avaliar e propor ajustes para o questionário desenvolvido, aplicaram-se 2 blocos de pré-testes. 0 primeiro feito somente com estudantes (com e sem viés ambiental) e o segundo com estudantes (com viés ambiental) e com consumidores em geral do varejo supermercadista.

Foi definido no primeiro pré-teste aplicar o questionário, que contava com a Escala de Consumo Sustentável e dados sociodemográficos, para 10 estudantes, sendo 5 estudantes do curso de Gestão 
Ambiental (ESALQ/USP) e 5 estudantes de outro curso de graduação - o curso foi o de Psicologia da UNIMEP Piracicaba.

Após este teste inicial, foi inserida, no questionário, uma pergunta aberta sobre consumo sustentável e então aplicou-se o segundo pré-teste com 6 estudantes do curso de Gestão Ambiental (ESALQ) e 6 consumidores no mercado de varejo de alta, média e baixa renda (2 por estabelecimento), a pesquisa foi feita em Americana.

Para alcançar o objetivo proposto para esta presente pesquisa, foram escolhidos dois perfis de consumidores para amostra.

O primeiro grupo foi composto por 173 estudantes universitários sabidamente engajados em causas ambientais de duas universidades renomadas da cidade de Piracicaba/SP, sendo estes: estudantes das diferentes séries dos Cursos de Bacharelado em Gestão Ambiental da Escola Superior de Agricultura Luiz de Queiroz (ESALQ/USP) e em Engenharia Ambiental da Escola de Engenharia de Piracicaba (EEP). A junção dos cursos se fez necessária para termos maior amostra e dados mais confiáveis. A população alvo foi considerada o número total de alunos presentes nas datas de aplicação dos questionários.

A coleta de dados, ocorrida entre junho e agosto de 2015 foi feita turma a turma durante o período de aulas, mediante prévia autorização dos professores presentes na sala de aula. A amostra final contou com 57 estudantes da EEP e 116 estudantes da ESALQ/USP.

Com o intuito de acessar uma amostra de consumidores em geral quanto às causas ambientais, 0 segundo grupo foi composto por 210 indivíduos recém-saídos de suas compras em supermercados da cidade de Piracicaba/SP, sendo estes localizados em bairros considerados de baixa, média e alta renda. Os estabelecimentos e regiões escolhidas para a coleta de dados foram: Supermercado Pague Menos, situado no bairro Santa Terezinha, como representante dos consumidores de baixa renda; Supermercado Delta, localizado no bairro Vila Areão, como representante nos consumidores de média renda; e, por fim, o Empório/Padaria do Vovô, situado no bairro São Judas, representando os consumidores de alta renda. A junção destas amostras em supermercados de diferentes classes sociais, fez-se necessária para termos uma amostra heterogênea.

A coleta de dados ocorreu nos meses de outubro, novembro e dezembro de 2015. Os questionários foram aplicados por meio de entrevista individual com consumidores que tinham acabado de fazer suas compras nos estabelecimentos em questão. Foram aplicados 70 questionários com consumidores de cada estabelecimento, totalizando 210 respondentes.

Inicialmente, os dados foram passados para uma planilha do Software Microsoft Excel ${ }^{\circledR}$, formando um banco de dados. Nesta etapa, procurou-se conferir os questionários preenchidos manualmente durante as entrevistas para verificar possíveis questionários incompletos. 
Dentre os 383 questionários finais desta pesquisa, a Escala de Consumo Sustentável foi respondida por completo, porém, alguns outros dados do questionário não foram respondidos pelos entrevistados. Dentre os estudantes, 28 não conseguiram responder sobre a renda familiar por não saberem, e um deles não respondeu a quantidade de pessoas que dividiam a renda familiar, mas por terem respondido corretamente as outras perguntas, foram considerados questionários válidos. No entanto, um questionário foi excluído por ter sido respondido por uma aluna francesa que estava em intercâmbio no Brasil. A exclusão foi feita por esta aluna possuir outra cultura e, consequentemente, opiniões distintas das dos brasileiros.

Após esta conferência, os dados foram transferidos para o software SPSS, versão 21, com o objetivo inicial de verificar a existência de valores perdidos (missings) e para a realização das análises dos dados que serão descritas a seguir.

Foram utilizadas estatísticas descritivas, como média e desvio-padrão para a realização das análises. A utilização destas ferramentas auxilia na interpretação de dados e na verificação da homogeneização da amostra. Para verificar se as dimensões da escala de Ribeiro e Veiga (2011) se repetem nos grupos deste estudo, foram utilizadas análises fatoriais. A análise de variância (ANOVA) também foi utilizada. Geralmente este tipo de análise mede estatísticas entre médias, examinando a variância dentro de um conjunto de dados (HAIR et al., 2014). Para avaliar as perguntas abertas inseridas nos questionários, foram utilizadas análises de conteúdo. Embora estas pesquisas qualitativas possam ser consideradas, por muitos profissionais, menos confiáveis que as quantitativas, conseguem fazer análises mais profundas. O pesquisador qualitativo busca, além de colher dados, conhecer os participantes da pesquisa (HAIR et al., 2014).

As perguntas foram avaliadas com o objetivo de categorizá-las em dois posicionamentos, sendo estes: referentes a pré-disposição ou não ao consumo sustentável. Automaticamente, respostas iniciadas como sim ou não foram alocadas em seus posicionamentos específicos. Respostas iniciadas como "às vezes", "depende", entre outras dentro deste mesmo sentido, foram inseridas no posicionamento de pré-disposição ao consumo sustentável, uma vez que, por meio destas respostas, observa-se que este indivíduo, mesmo não agindo na totalidade, pensa de certa maneira no impacto que seu consumo causa no meio ambiente.

\section{RESULTADOS E ANÁLISE DOS DADOS}

\subsection{CARACTERIZAÇÃO DA AMOSTRA}

A amostra, conta com 172 estudantes identificados como consumidores com formação ambiental e com 210 consumidores identificados como consumidores em geral, totalizando 382 participantes. Com 
relação ao gênero, a amostra apresentou 59,9\% dos consumidores com formação ambiental e 60,5\% dos consumidores em geral como sendo do gênero feminino.

A idade mínima foi de 17 anos para ambos os grupos pesquisados e a máxima foi de 58 anos para o grupo dos consumidores com formação ambiental e 75 anos para o grupo dos consumidores em geral. Nesta variável, observou-se grande diferença entre as médias de idade da população pesquisada, sendo 22,37 anos em média para os consumidores com formação ambiental e 36,33 anos em média para os consumidores em geral, explicado pelo fato do grupo com menor média de idade ser de estudantes universitários que ingressam no ensino superior continuando os estudados após finalização do ensino médio.

Em relação ao nível de escolaridade, o grupo de consumidores com formação ambiental consequentemente apresenta resultados iguais ou acima do nível superior incompleto, sendo este 90,7\% da amostra. Já entre os consumidores em geral, considerando o nível de escolaridade dos que estejam cursando ou já cursaram curso superior, temos um total de 46,2\%, representando uma amostra com conhecimento e informação acima da média nacional.

Na variável relacionada à renda familiar, apenas 144 questionários dos estudantes, representados pelos consumidores com formação ambiental, foram considerados válidos, uma vez que 28 deles não puderam responder a renda por não saber. Entre os consumidores com formação ambiental, a média de renda familiar foi de $\mathrm{R} \$ 5.727,48$. O grupo de consumidores em geral apresentou média de renda de $R \$ 3.759,43$.

Após caracterização da amostra, avançamos para as análises envolvendo a Escala de Consumo Sustentável de Ribeiro e Veiga (2011).

\subsection{DIFERENÇAS ENTRE OS SEGMENTOS ANALISADOS}

Com relação à pergunta aberta feita aos grupos pesquisados, avaliamos as respostas encaixandoas em 2 grupos, pessoas pré-dispostas ou não ao consumo sustentável. Foi observado que o consumo sustentável é praticado por 78,5\% dos consumidores com formação ambiental e por 40,5\% dos consumidores em geral.

Contando com quase $80 \%$ da amostra, os consumidores com formação ambiental se mostraram mais pré-dispostos a consumir de forma responsável e sustentável, provavelmente motivados pelo conhecimento que adquiriram no decorrer dos cursos ou simplesmente por suas características pessoais estarem mais ligadas a temas envolvendo o meio ambiente. Para Anderson Jr. e Cunninghan (1972), 
as características pessoais relacionadas aos relacionamentos pessoais e com a sociedade são as mais eficazes para definir consciência social responsável.

Por sua vez, quase $60 \%$ da amostra dos consumidores em geral optam por consumir sem pensar no meio ambiente. Durante as entrevistas, muito destes consumidores se mostraram motivados a consumir de forma a maximizar suas necessidades pessoais e financeiras, deixando o meio ambiente de lado.

Para comparar as diferenças entre os grupos deste estudo, no que tange às questões da Escala de Consumo Sustentável, utilizou-se a análise ANOVA, conforme tabela 1.

Ao avaliar as médias entre os itens da escala, observou-se que o grupo de consumidores com formação ambiental possui maiores médias na maioria das variáveis, dentre elas, destacam-se as variáveis relacionadas à reciclagem, cujas médias foram maiores que nos demais itens, apresentando média de 3,96 para reciclagem de metal, 4,05 para reciclagem de vidro, 4,02 para reciclagem de papel e 4,10 para reciclagem de plástico. Entre o grupo de consumidores em geral as variáveis referentes à reciclagem também apresentaram boas médias, porém bem menores em comparação ao primeiro grupo, sendo 3,52 para reciclagem de metal, 3,58 para reciclagem de vidro, 3,35 para reciclagem de papel e 3,45 para reciclagem de plástico. 0 grau de significância foi baixo, mostrando comportamento distinto entre os grupos do estudo. 
Tabela 1 - ANOVA - Escala de Consumo Sustentável versus formação ambiental ou não

\begin{tabular}{|c|c|c|c|c|c|c|c|c|}
\hline & & \multirow{2}{*}{$\mathbf{N}$} & \multirow{2}{*}{ Média } & \multirow{2}{*}{$\begin{array}{l}\text { Desvio } \\
\text { padrão }\end{array}$} & \multicolumn{2}{|c|}{$\begin{array}{c}\text { htervalo de coafiança } \\
\text { de } 95 \%\end{array}$} & \multirow{2}{*}{$\mathbf{F}$} & \multirow{2}{*}{ Sig. } \\
\hline & & & & & $\begin{array}{c}\text { Limite } \\
\text { Inferior }\end{array}$ & $\begin{array}{c}\text { Limite } \\
\text { Superior }\end{array}$ & & \\
\hline \multirow{3}{*}{$\begin{array}{l}\text { Separo objetos de metal (latas de } \\
\text { aluminio, óleo, extrato de tomate, } \\
\text { etc) para reciclagem }\end{array}$} & Grupo 1 & 172 & 3,96 & 1,91 & 3,78 & 4,14 & \multirow{3}{*}{10,005} & \multirow{3}{*}{0,002} \\
\hline & Grupo 2 & 210 & 3,52 & 1,448 & 3,33 & 3,72 & & \\
\hline & Total & 382 & 3,72 & 1,355 & 3,58 & 3,86 & & \\
\hline \multirow{4}{*}{$\begin{array}{l}\text { Nas eleições para cargos publicos, prefiro } \\
\text { votar em can didatos que têm posições } \\
\text { firmes em defesa do meio ambiente. }\end{array}$} & Grupo 1 & 172 & 3,77 & 1,082 & 3,61 & 394 & \multirow{3}{*}{17,393} & \multirow{3}{*}{0,000} \\
\hline & Grupo 2 & 210 & 3,26 & 1,294 & 3,08 & 3,43 & & \\
\hline & Total & 382 & 3,49 & 1,229 & 3,37 & 3,61 & & \\
\hline & Grupo 1 & 172 & 3.67 & 1,075 & 3,51 & 3,84 & \multirow{3}{*}{7,202} & \multirow{3}{*}{0,008} \\
\hline \multirow[t]{2}{*}{ Busco man eiras de reutilizar objetos. } & Grupo 2 & 210 & 3,37 & 1,147 & 3,21 & 3,52 & & \\
\hline & Total & 382 & 3,51 & 1,124 & 3,39 & 3.62 & & \\
\hline \multirow{3}{*}{$\begin{array}{l}\text { Tento consertar as coisas emvez de } \\
\text { jogálas fora. }\end{array}$} & Grupo 1 & 172 & 3,66 & 1,089 & 3,49 & 3,82 & \multirow{3}{*}{0,485} & \multirow{3}{*}{0,487} \\
\hline & Grupo 2 & 210 & 3,74 & 1,167 & 3,58 & 3,9 & & \\
\hline & Total & 382 & 3,7 & 1,132 & 3,59 & 3,82 & & \\
\hline \multirow{3}{*}{$\begin{array}{l}\text { Separo vidros (garrafas de cerveja, } \\
\text { refrigerante, frascos de perfume } \\
\text { etc) para reciclagem }\end{array}$} & Grupo 1 & 172 & 4,05 & 1,276 & 3.86 & 4,24 & \multirow{3}{*}{10,454} & \multirow{3}{*}{0,001} \\
\hline & Grupo 2 & 210 & 3,58 & 1,524 & 3,37 & 3,79 & & \\
\hline & Total & 382 & 3,79 & 1,435 & 3,65 & 394 & & \\
\hline \multirow{4}{*}{$\begin{array}{c}\text { Paro de comprar de uma empresa que } \\
\text { mostra desrespeito pelo meio } \\
\text { ambiente. }\end{array}$} & Grupo 1 & 172 & 3,19 & 1,171 & 3,02 & 3,37 & \multirow{3}{*}{0,819} & \multirow{3}{*}{0,366} \\
\hline & Grupo 2 & 210 & 3,07 & 1,472 & 2,87 & 3,27 & & \\
\hline & Total & 382 & 3,12 & 1,345 & 2,99 & 3,26 & & \\
\hline & Grupo 1 & 172 & 3,02 & 1,134 & 0,086 & 285 & & \\
\hline Compro produtos usados. & Grupo 2 & 210 & 2,23 & 1,010 & 0,070 & 2,09 & 52,412 & 0,000 \\
\hline & Total & 382 & 2,59 & 1,137 & 0,058 & 2,47 & & \\
\hline Mudo de marca para comprar de & Grupo 1 & 172 & 3,39 & 1,079 & 3,23 & 3,55 & & \\
\hline empres as que demonstram maior cuidado & Grupo 2 & 210 & 3,02 & 1,212 & 2,85 & 3,19 & 9,187 & 0,003 \\
\hline com o meio ambiente. & Total & 382 & 3,19 & 1,201 & 3,07 & 3,31 & & \\
\hline Deiwo aparelhos como televisăo e & Grupo 1 & 172 & 2,03 & 1,070 & 1,87 & 2,20 & & \\
\hline computador ligados mesmo quando nào & Grupo 2 & 210 & 1,78 & 1,103 & 1,63 & 1,93 & 5,340 & 0,021 \\
\hline estou os utilizando. & Total & 382 & 1,89 & 1,095 & 1,78 & 2,00 & & \\
\hline Separo papéis Gornais, revistas, livros, & Grupo 1 & 172 & 4,02 & 1,233 & 3,84 & 4,21 & & \\
\hline cadernos, etc) para reciclagem. & Grupo 2 & 210 & 3,35 & 1,531 & 3,14 & 3,56 & 21,883 & 0,000 \\
\hline & Total & 382 & 3,65 & 1,442 & 3,51 & 3,80 & & \\
\hline Fecho as tomeiras da pia ou do chuveiro & Grupo 1 & 172 & 3,84 & 1,110 & 3,68 & 4,01 & & \\
\hline quando es tou ensaboando os & Grupo 2 & 210 & 3,63 & 1,300 & 3,45 & 3,81 & 2,931 & 0,088 \\
\hline objetos, o corpo ou as màos. & Total & 382 & 3,73 & 1,221 & 3,60 & 3,85 & & \\
\hline & Grupo 1 & 172 & 1,65 & 0,909 & 1,51 & 1,78 & & \\
\hline Deixo luzes acesas sem necessidade. & Grupo 2 & 210 & 1,62 & 1,097 & 1,47 & 1,77 & 0,063 & 0,802 \\
\hline & Total & 382 & 1,63 & 1,016 & 1,53 & 1,73 & & \\
\hline Separo embalagens de plástico (sacolas, & Grupo 1 & 172 & 4,10 & 1,168 & 3,92 & 4,27 & & \\
\hline sacolas PET, copos descartaveis, etc) & Grupo 2 & 210 & 3,45 & 1,503 & 3,25 & 3,66 & 21,289 & 0,000 \\
\hline para reciclagem & Total & 382 & 3,74 & 1,398 & 3.6 & 3,88 & & \\
\hline
\end{tabular}

Legenda: Grupo 1 - consumidores com formação ambiental | Grupo 2 - consumidores em geral Fonte: Dados da pesquisa 
Retomando Ebreo e Vinning (2001), os avanços tecnológicos para minimizar os efeitos negativos na natureza não são suficientes para diminuir significativamente a degradação ambiental, e somente com a ação individual e das comunidades poderemos ter resultados mais promissores quanto à sustentabilidade.

Entre os consumidores em geral, os itens que apresentaram maiores médias estão relacionados à frugalidade e à economia de recursos, sendo elas: tento consertar as coisas em vez de jogá-las fora, com 3,74, deixo aparelhos como televisão e computador ligados mesmo quando não os estou utilizando e deixo luzes acesas sem necessidade; e possuindo valores invertidos, sendo considerado como melhor o menor número, apresentaram respectivamente médias de 1,78 e 1,62. Vale lembrar que estas variáveis estão ligadas, além da economia de recursos à economia financeira.

Nos outros resultados obtidos com a análise ANOVA, observou-se que a maioria dos itens demostra significância muita baixa. A interpretação correta deste número é que quanto mais baixa a significância, maiores são as diferenças reais nas médias de probabilidade de retorno (HAIR et al., 2014). Portanto, para estes itens, pode ser considerado que existe diferença significativa entres as respostas dadas pelos grupos de estudo. Destaca-se quatro itens onde a significância encontrada foi alta: tento consertar as coisas em vez de jogá-las fora; paro de comprar de uma empresa que mostra desrespeito ao meio ambiente; fecho as torneiras da pia ou do chuveiro quando estou ensaboando os objetos, o corpo ou as mãos e deixo as luzes acesas sem necessidade e, portanto, com respostas semelhantes entre os consumidores com formação ambiental e os consumidores em geral. O consumo sustentável abrange também comportamentos em prol ao meio ambiente, como por exemplo, utilizar menos vezes o automóvel, ajudar na reciclagem dos produtos separando em casa os diferentes tipos de resíduos, prezar pela economia de recursos e energia, buscando, assim, a frugalidade e o desenvolvimento de uma consciência ecológica (SHAMDASANI; CHONLIN; RICHMOND, 1993).

Entre os itens com significância alta, temos: tento consertar as coisas em vez de jogá-las fora, com significância de 0,487. A média deste item, conforme escrito acima, foi maior no grupo de consumidores em geral, e o item está dentro da dimensão frugalidade (RIBEIRO; VEIGA, 2011), porém está ligado à economia financeira, fator muito levantado pelos entrevistados.

O item paro de comprar de uma empresa que mostra desrespeito pelo meio ambiente também apresentou significância alta, com 0,366. A dimensão de tal item é a consciência ecológica (RIBEIRO; VEIGA, 2011) e apresentou-se mais forte no grupo de consumidores com formação ambiental.

O item fecho as torneiras da pia ou do chuveiro quando estou ensaboando os objetos, o corpo ou as mãos apresentou significância de 0,088 mostrando ter respostas distintas entre os grupos. Encontrado na dimensão de economia de recursos (RIBEIRO; VEIGA, 2011), este item pode estar relacionado também à economia financeira. Para análise deste item, cabe voltarmos no tempo, onde, em 2015, período em que a 
pesquisa foi feita, tivemos uma crise hídrica no Brasil, com maior ênfase na região sudeste. As reportagens sobre água e o desperdício foram priorizadas nas mídias, além disso, um aumento significativo na conta de água dos paulistanos devidos às divisões de bandeira verde, amarela e vermelha pode ter gerado esta diferença entre os grupos, uma vez que boa parte da população preza pela economia financeira.

0 item deixo as luzes acesas mesmo sem necessidade foi o que apresentou maior significância, chegando a 0,802. Este item também está relacionado à conjuntura de 2015 com a crise hídrica vivida pelo País, e com consequente aumento no valor da energia elétrica, fazendo com que as pessoas pensassem mais na economia financeira do que na economia de recursos.

\subsection{ANÁLISE FATORIAL}

Buscando relacionar as respostas dadas aos itens da Escala de Consumo Sustentável utilizada na pesquisa, realizou-se uma análise fatorial para cada um dos grupos de estudo.

Feita a análise fatorial para o grupo de consumidores com formação ambiental (quadro 2) e para o grupo de consumidores em geral (quadro 3), foram encontradas duas dimensões idênticas com o estudo de Ribeiro e Veiga (2011), sendo elas reciclagem e consciência ecológica, e duas dimensões bem diferentes abrangendo frugalidade e economia de recursos.

A dimensão de Reciclagem, com seus quatro itens, separo embalagens de plástico (sacolas, garrafas PET, copos descartáveis etc.) para reciclagem; separo objetos de metal (latas de alumínio, óleo, extrato de tomate etc.) para reciclagem; separo papéis (jornais, revistas, livros, cadernos etc.) para reciclagem; e separo vidro (garrafas de cerveja, refrigerante, frascos de perfumes etc.) para reciclagem, mostrou-se semelhante para os dois grupos de estudo apresentando cargas fatoriais satisfatórias.

A dimensão de Consciência ecológica composta de três itens, paro de comprar de uma empresa que mostra desrespeito pelo meio ambiente; mudo de marca para comprar de empresas que demonstram maior cuidado com o meio ambiente; e nas eleições para cargos públicos, prefiro votar em candidatos que têm posições firmes em defesa do meio ambiente, também se apresentou semelhante entre os grupos estudados.

A dimensão Frugalidade apresentou diferença entre os grupos de consumidores com formação ambiental e o grupo de consumidores em geral. Entre os consumidores com formação ambiental, os três fatores apontados por Ribeiro e Veiga (2011) como itens da dimensão Frugalidade, tento consertar as coisas em vez de jogá-las fora; busco maneiras de reutilizar objetos; e compro produtos usados, apareceram agrupados junto a um quarto item, que apesar de apresentar uma carga fatorial baixa e insatisfatória, foi considerado para mantê-lo nas análises, o item em questão, fecho as torneiras da pia ou do chuveiro quando 
estou ensaboando os objetos, o corpo ou as mãos, apresentou-se agrupado na categoria de frugalidade. Isto pode ser explicado pela crise hídrica vivida em 2015, conforme descrito no tópico anterior.

Entre os consumidores em geral, no que tange à frugalidade, apenas dois itens se mantiveram unidos, tento consertar as coisas em vez de jogá-las fora; busco maneiras de reutilizar objetos. 0 terceiro item, compro produtos usados, passou para outra dimensão. Segundo Ribeiro e Veiga (2011), este item apresentou medidas menos consistentes, sendo necessários, a título de ilustração, ajustes como: "compro produtos usados, como carros e equipamentos seminovos".

E por fim, a dimensão Economia de recursos apresentou resultados bem diferentes entre os grupos estudados. Entre os consumidores com formação ambiental, dois itens mantiveram-se na mesma dimensão apontada por Ribeiro e Veiga (2011): deixo aparelhos como televisão e computador ligados mesmo quando não os estou utilizando e deixo luzes acesas sem necessidade. 0 terceiro item apontado por Ribeiro e Veiga (2011) como sendo integrante desta dimensão, fecho as torneiras da pia ou do chuveiro quando estou ensaboando os objetos, o corpo ou as mãos, como discutido anteriormente, embora tenha apresentado carga fatorial baixa, passou a ser considerado um item da dimensão frugalidade.

\section{Quadro 2 - Análise fatorial - Consumidores com formação ambiental}

\begin{tabular}{|c|c|c|c|c|}
\hline Itens da Escala de Consumo Sustentável & \multicolumn{4}{|c|}{ Carga Fatorial } \\
\hline \multicolumn{5}{|l|}{ Dimens ão Reciclagem } \\
\hline Separo emba lagens de plas tico (sacolas, garrafas PET, copos des cartáveis, etc) para recic lagem & 0,938 & & & \\
\hline Separo obietos de metal (latas de ahminio, ólao, extra to de toena tes, etc) para recicla gen. & 0,919 & & & \\
\hline Separo pa péis (jomais, revistas, liwros, cademos, etc) para rec icla gem. & 0,844 & & & \\
\hline Separo vidro (garrafas de cerve ia, fefrigerante, frascos de perfumes, etc) para reciclagem. & 0,842 & & & \\
\hline \multicolumn{5}{|l|}{ Dimeus ão Frugalidade } \\
\hline \multicolumn{2}{|l|}{ Tento consertar as coisas en vez de iogá-las fora. } & \multicolumn{3}{|l|}{0,833} \\
\hline \multicolumn{2}{|l|}{ Busco maneiras de reutilizar os objetos. } & \multicolumn{3}{|l|}{0,768} \\
\hline \multicolumn{2}{|l|}{ Compro produtos usad os. } & \multicolumn{3}{|l|}{0,598} \\
\hline \multicolumn{2}{|l|}{ Fecho as tome iras da pia ou do cha veiro, quando estou ensa boando os objetos, o corpo ou as mãos } & \multicolumn{3}{|l|}{0,388} \\
\hline \multicolumn{5}{|l|}{ Dimens ão Consciência Ecológica } \\
\hline \multicolumn{2}{|l|}{ Paro de comprar de enpresas que mons tran desre spe ito ao meio an biente } & \multicolumn{3}{|c|}{0,774} \\
\hline \multicolumn{2}{|l|}{ Mudo de marcas para comprar de enpres as que demons tram respeito pelo me io ambiente } & \multicolumn{3}{|c|}{0,724} \\
\hline \multicolumn{2}{|l|}{ Nas elaiçōes para cargos púb licos, prefiro votar en candida tos que ten pos içōes firmes en defes a ambiente } & \multicolumn{3}{|c|}{0,09} \\
\hline \multicolumn{5}{|l|}{ Dimens ão Ecou omia de Rec uros } \\
\hline \multicolumn{2}{|l|}{ Deiro a pareth os como te levis ảo e computad or mesmo quando nảo estou os utilizando } & \multicolumn{3}{|r|}{0,830} \\
\hline \multicolumn{2}{|l|}{ Deino ahues aces as sem neces sidada } & \multicolumn{3}{|r|}{0,731} \\
\hline
\end{tabular}

Fonte: elaborado pelos autores 


\section{Quadro 3 - Análise fatorial - Consumidores em geral}

\begin{tabular}{|c|c|c|c|}
\hline Itens da Escala de Consumo Sustentável & & \multicolumn{2}{|l|}{ Carga Fatorial } \\
\hline \multicolumn{4}{|l|}{ Dimens ão Reciclagem } \\
\hline Separo emba lagens de plas tico (sacolas, garrafas PET, copos des cartáveis, etc) para recic lagem & 0,928 & & \\
\hline Separo objetos de metal (latas de ahun inio, ólao, extra to de toma tes, etc) para reciclagen. & 0,921 & & \\
\hline Separo vidro (garrafas de cerve ja, refrigerante, fra scos de perfuenes, etc) para reciclagen. & 0,878 & & \\
\hline Separo papéis (jomais, revistas, livros, cademos, etc) para recicla gen. & 0,875 & & \\
\hline \multicolumn{4}{|l|}{ Dimensão Consciência Ecológica } \\
\hline \multicolumn{2}{|l|}{ Paro de comprar de empresas que mons tram desre spe ito ao meio ambiente } & \multicolumn{2}{|l|}{0,852} \\
\hline \multirow{2}{*}{\multicolumn{2}{|c|}{ Mudo de marcas para comprar de empres as que demons tran respeito pelo me io ambiente }} & \multicolumn{2}{|l|}{0,785} \\
\hline Nas ele icôes para cargos púb licos, prefiro votar em candida tos que ten pos içôes fimes en defes a ambiente & & 0,749 & \\
\hline \multicolumn{4}{|c|}{ Dimens ão Frugalidade } \\
\hline \multicolumn{2}{|l|}{ Tento consertar as coisas en vez de jogá-las fora. } & 0,732 & \\
\hline \multicolumn{2}{|l|}{ Busco maneiras de reutilizar os objatos. } & 0,686 & \\
\hline \multicolumn{4}{|l|}{ Dimens ão Ecou omia de Rec uros } \\
\hline \multicolumn{2}{|l|}{ Deiro a pareth os como te lavis ảo e computad or me smo quando nảo estou os utilizando } & \multicolumn{2}{|l|}{0,338} \\
\hline \multicolumn{2}{|l|}{ Compro produtos usad os. } & \multicolumn{2}{|l|}{0,876} \\
\hline \multicolumn{2}{|l|}{ Fecho as tome iras da pia ou do cha veiro, quando estou ensa boando os objetos, o corpo ou as mãos } & \multicolumn{2}{|l|}{0,526} \\
\hline \multicolumn{4}{|l|}{ Dimens ão Ecou omia Financeira } \\
\hline Deiro huzes acesas sem necess idade & & & 0,855 \\
\hline
\end{tabular}

\section{Fonte: elaborado pelos autores}

Entre os consumidores em geral, os itens deixo aparelhos como televisão e computador ligados mesmo quando não os estou utilizando e fecho as torneiras da pia ou do chuveiro quando estou ensaboando os objetos, o corpo ou as mãos permaneceram unidos junto a um terceiro item, compro produtos usados. Ao avaliarmos os motivos destes itens se agruparem para este grupo de estudo, concluise que os mesmos envolvem, além de economia de recursos e frugalidade, uma economia financeira, possível motivação para este resultado. 0 item deixo aparelhos como televisão e computador ligados mesmo quando não os estou utilizando também permaneceu nesta análise mesmo apresentando carga insatisfatória.

Embora haja diferenças encontradas entre os grupos, e o trabalho de Ribeiro e Veiga (2011) seja significativo, uma quinta dimensão, encontrada entre os consumidores em geral, pode ser considerada a diferença mais gritante. $\mathrm{O}$ item deixo luzes acesas sem necessidades, integrante do grupo de economia de recursos, segundo Ribeiro e Veiga (2011), apresentou-se isolado dos demais itens, provavelmente influenciado pelo crescente aumento de preço da energia elétrica vivido em 2015, e sendo considerado pelo autor como sendo uma dimensão ligada à economia financeira. 


\section{CONSIDERAÇÕES FINAIS}

Após as análises discutidas na seção anterior, apresentamos a seguir a conclusão final deste trabalho, verificando o atendimento dos objetivos propostos.

\subsection{CONCLUSÕES DO ESTUDO}

Este estudo tinha como objetivo pesquisar o consumo sustentável e verificar se o nível de consumo sustentável entre consumidores em geral e os consumidores envolvidos em questões relacionadas ao meio ambiente se diferem. Para tanto, foi utilizada uma Escala de Consumo Sustentável proposta por Ribeiro e Veiga (2011), uma pergunta aberta sobre práticas de consumo, além de um questionário levantando variáveis sociodemográficas.

No primeiro momento, cabe destacar os grupos de estudo. Para representar os consumidores envolvidos em questões ambientais, foi escolhido trabalhar com alunos de duas instituições renomadas de Piracicaba/SP, matriculados em cursos superiores na temática ambiental. Para representar os consumidores em geral, foram escolhidos, por conveniência, indivíduos recém-saídos de suas compras em supermercados, localizados em regiões distintas de Piracicaba/SP, buscando com isto uma amostra heterogênea destes consumidores.

Por meio das amostras detalhadas nas seções anteriores, é possível responder o objetivo geral do trabalho, indicando que uma pré-disposição ao consumo sustentável está mais presente em pessoas que estão envolvidas com questões ambientais do que em outros tipos de consumidores.

No que tange à aplicação da Escala de Consumo Sustentável entre grupos de pessoas com formação ambiental e sem viés de formação ambiental, é possivel afirmar que a escala é bem abrangente e pode medir a consciência ambiental em ambos os grupos. No entanto, as condições ambientais vividas no país durante a coleta de dados demostraram que a escala pode ter suas dimensões alteradas.

Com estes resultados, foi possível contribuir com as implicações teóricas e gerenciais relacionadas à prática do consumo sustentável. A utilização da Escala de Consumo Sustentável proposta por Ribeiro e Veiga (2011), relativamente recente e desenvolvida no Brasil, apesar de aplicada em um conceito diferente do original, apresentou-se como uma boa escala para medir o consumo sustentável, tanto em grupos de pessoas com formação ambiental e ou grupos de pessoas sem esta formação.

Outro fator importante foi o resultado obtido com relação à pré-disposição ao consumo sustentável, mostrando uma possível tendência a esta prática na cidade de Piracicaba/SP. Os resultados encontrados nos grupos estudados poderão ser trabalhados em outras pesquisas, com o objetivo de comparações 
entre os mesmos. Em suma, a confirmação de diferenças entre os grupos estudados cumpriu o objetivo do estudo, consistindo assim num avanço da teoria, sendo esta a implicação mais importante.

Como mencionado na introdução deste trabalho, empresas estão investindo em ações sociais buscando se identificar com seus públicos alvo. Ao apontar uma crescente prática de consumo sustentável, estas poderão realizar campanhas direcionadas e aumentar suas ações sustentáveis, podendo colher bons resultados financeiros.

Portanto, reconhecer que a pré-disposição ao consumo sustentável está presente entre os consumidores é um fator extremamente importante para continuar os estudos nesta temática e para que empresas permaneçam atendendo seus clientes e suas novas necessidades.

Após a finalização deste estudo, podemos destacar algumas limitações. Primeiramente, é necessário salientar que estudos desta natureza envolvem questões éticas, e que os entrevistados possam se dispor a responder conforme se é esperado pela sociedade, principalmente entre os estudantes que estão matriculados em cursos ligados à esfera ambiental.

Um segundo fator refere-se ao corte transversal da pesquisa, onde os dados foram colhidos em determinado período de tempo, no caso deste estudo, em meio a uma crise hídrica que o País viveu, principalmente na região sudeste onde está localizada a cidade de Piracicaba/SP. Destaca-se, também, limitações referentes à amostra. A população delimitada ocorreu na cidade de Piracicaba/SP. No entanto, aspectos culturais podem influenciar este estudo.

Com relação aos estudos futuros, reaplicá-lo em outros locais, com culturas diferentes, poderá apresentar resultados diferentes, confirmando ou negando que fatores culturais possam influenciar no ato de consumir sustentavelmente.

\section{REFERÊNCIAS}

AKATU. Disponivel em: <http://www.akatu.org.br/Temas/Consumo-Consciente/Posts/Pesquisa-revela-que-oito-em-dez-brasileiros-reconhecem-selos-com-atributos-ambientais/>. Acesso em: 16 mai. 2016.

ANDERSON JR, W.T.; CUNNINGHAM, W.H. The socially conscious consumer. Journal of Marketing, v. 36, p. 23-31, jul. 1972.

CHEN, T; CHAl, L. Attitude towards the environment and green products: consumers' perspective", Management Science and Engineering, v. 4, n. 2, p. 27-39, 2010. 
EBREO, A.; VINNING, J. How similar are recycling and waste reduction? Future orientation and reasons for reducing waste as predictors of self-reported behavior. Environment and Behavior, Thousand Oaks, CA, v. 33, n. 3, p. 424-448, may. 2001.

ENGEL, J. F.; BLACKWELL, R. D.; MINIARD, P. Comportamento do consumidor. Rio de Janeiro, LTC, 2000.

FRAJ, E.; MARTINEZ, E. Ecological consumer behavior: an empirical Analysis. International Journal of Consumer Studies, v. 31, n. 1, p. 26-33, jan. 2007.

FONTENELLE, I.A. A produção do discurso do consumidor responsável na mídia de negócios: crítica e assimilação da crítica no movimento anti-marcas. In: XXXXIV Encontro ANPAD, 2010, Rio de Janeiro.

Anais... Rio de Janeiro: ANPAD, 2010.

GONÇALVES-DIAS, S. et al. Consciência Ambiental: um estudo exploratório sobre suas implicações para o ensino de administração. RAE-eletrônica, v. 8, n. 1, Art. 3, jan./jun. 2009.

HAIR, J. F. et al. Fundamentos de pesquisa de marketing. 3. ed. Porto Alegre, AMGH, 2014.

HANSEN, U.; SCHRADER, U. A modern model of consumption for a sustainable society. Journal of Consumer Policy, v. 20, p. 443-468, 1997.

HANSEN, Torben; SØRENSEN, Maria Ingerslev; ERIKSEN, Marie-Louise Riewerts. How the interplay between consumer motivations and values influences organic food identity and behavior. Food Policy, v. 74, p. 39-52, 2018.

MALONEY, M. P.; WARD, M.P. Ecology: let's hear from the people. An objective scale for the measurement of ecological atitudes and knowledge. American Psychologist, Washington, DC, v. 28, n. 7, p. 583586, jul. 1973.

MALONEY, M. P.; WARD, M. P.; BRAUCHT, G. N. Psychology in action: a revised scale for the measurement of ecological atitudes and kwowledge. American Psychologist, Washington, DC, v. 30, n. 7, p. 787790, jul. 1975.

MACEDO, L.C.; FERRARI, M.A. O papel da comunicação no processo de sustentabilidade: um estudo nas empresas varejistas de grande porte do Estado de São Paulo. Comunicologia - Revista de comunicação e Epistemologia da Universidade Católica de Brasília, Brasília, p. 281-302, 2014.

MATSUMOTO, Mitsutaka; CHINEN, Kenichiro; ENDO, Hideki. Remanufactured auto parts market in Japan: Historical review and factors affecting green purchasing behavior. Journal of Cleaner Production, v. 172, p. 4494-4505, 2018. 
MINISTÉRIO DO MEIO AMBIENTE. Disponível em: <http://www.mma.gov.br/responsabilidade-socioambiental/producao-e-consumo-sustentavel/conceitos/consumo-sustentavel/>. Acesso em: 13 mai. 2016.

MINISTÉRIO DO MEIO AMBIENTE. Disponível em: <http://www.mma.gov.br/responsabilidade-socioambiental/agenda-21/agenda-21-global/> Acesso em: 17 mai. 2016

MOREIRA, M. M.; SOARES, C. A. P. Ética e responsabilidade social ambiental na gestão de empresas da indústria da construção civil - uma pesquisa de campo em empresas do setor. In: CONGRESSO NACIONAL DE EXCELÊNCIA EM GESTÃO, 4., 2008, Niterói. Anais..., Niterói: CNEG, p. 1-23, 2008.

ONU. Transformando Nosso Mundo: A agenda 2030 para o Desenvolvimento Sustentável, Unic Rio, 2016. Disponivel em: <http://www.pnud.org.br/Docs/Agenda2030completo_PtBR.pdf>. Acesso em: 01 set. 2017.

OTTMAN, J.A. Marketing verde. São Paulo Makron Books, 1993 - verificar em artigo ou o livro.

PEATTIE, K. Towards sustainability: the third age of green marketing. The Marketing Review, Scotland, UK, v. 2, n. 2, p. 129-146, dec. 2001.

PINTO, D.C. Valores e motivação baseada na identidade: a influência da identidade no consumo responsável. Dissertação de Mestrado. UFRGS, 2011.

PORTILHO, F. Sustentabilidade, Consumo e Cidadania. ed. 2, São Paulo, Cortez, 2010.

RIBEIRO, J.A.; VEIGA, R.T. Proposição de uma Escala de Consumo Sustentável. RAUSP - Revista de Administração., São Paulo, v. 46, n. 1, p. 45-60, jan./fev./mar. 2011.

ROBERTS, J.A. Green Consumers in the 1990s: Profile and implications for advertising. Journal os Business Research, New York, NY, v. 36, n. 3, p. 217-231, jul. 1996.

SALEEM, Muhammad Abid; EAGLE, Lynne; LOW, David. Climate change behaviors related to purchase and use of personal cars: Development and validation of eco-socially conscious consumer behavior scale. Transportation Research Part D: Transport and Environment, v. 59, p. 68-85, 2018.

SCHAEFER, A.; CRANE, A. Adressing sustainability and consumption. Journal of Macromarketing, Thousand Oaks, CA, v. 25, n. 1, p. 76-92, jun. 2005.

SCHLEGELMILCH, B. B; BOHLEN, G. M.; DIAMANTOPOULOS, A. The link between green purchasing decisions and measures of evironmental consciousness. European Journal of Marketing, v. 30, n. 5, p. 35$55,1996$. 
SHAMDASAMI, P.; CHON-LIN, G. O.; RICHMOND, D. Exploring green consumers in na oriental culture: role of personal and marketing mix. Adavances in Consumer Research, Provo, UT, v. 20, n. 1, p. 488-493, 1993.

SOLOMOM, M. R. 0 comportamento do consumidor. Comprando, possuindo e sendo. 5.ed. Porto Alegre, Bookman, 2002.

STRAUGHAN, R. N.; ROBERTS, J.A. Environmental segmentation alternatives: a look at green consumer behavior in the new millennium. Journal of Consumer Marketing, West Yorkshire, UK, v. 16, n. 6, p. 558575, jun. 1999.

VEIGA-NETO, Alipio Ramos et al. Environmental Favorability: Evidence in the Brazilian Context of Consumer Generations. Mediterranean Journal of Social Sciences, v. 9, n. 1, p. 181, 2018.

VERMEIR, I.; VERBEKE, W. Sustainable food consumption among young adults in Belgium: Theory of planned behaviour and the role of confidence and values. Ecological Economics, 64, p. 542-553, 2008. 